\title{
PENGIKLANAN BIDANG KEPAKARAN PEGUAM: KEPERLUANNYA DALAM MEMBANTU BAKAL KLIEN MEMILIH PEGUAM
}

\author{
Harlina Mohamed On*
}

\begin{abstract}
Abstrak
Dalam konteks pengiklanan oleh peguam, menjadi kewajipan profesion guaman untuk mendidik masyarakat, khususnya mereka yang berpendapatan sederhana dan rendah, mengenai kewujudan dan kesediaan perkhidmatan guaman dalam membantu mereka menyelesaikan sesuatu masalah perundangan. Lantaran itu, iklan mengenai perkhidmatan guaman wajar mengandungi maklumat yang relevan untuk diketahui umum. Walau bagaimanapun, melihat kepada kaedah publisiti yang mengawal profesion guaman Malaysia, maklumat yang boleh diiklankan sebahagian besarnya terbatas kepada biodata peguam serta butiran mengenai firma dan rakan kongsi peguam. Maklumat lain yang lebih penting untuk diketahui awam, yang boleh membantu mereka untuk membandingkan perkhidmatan yang wujud di pasaran, serta memilih perkhidmatan peguam mana yang bersesuaian dengan keperluannya, tidak boleh diiklankan. Salah satunya ialah maklumat mengenai bidang kepakaran peguam. Berdasarkan metod analisis kandungan, kertas kerja ini membincangkan tentang sekatan untuk mengiklankan bidang kepakaran seperti yang terkandung dalam kaedah publisiti yang mengawal profesion guaman Malaysia, serta membuat perbandingan dengan peraturan yang dikuatkuasakan di Amerika Syarikat, United Kingdom (England \& Wales) dan Australia (New South Wales). Berdasarkan pensampelan mudah, soal selidik untuk meninjau persepsi awam dan peguam berhubung isu ini turut diedarkan dan dapatannya dipersembahkan secara deskriptif. Hasil kajian menunjukkan bahawa majoriti pihak peguam dan awam mempunyai persepsi bahawa maklumat mengenai bidang kepakaran adalah maklumat yang sesuai untuk diiklankan oleh peguam.
\end{abstract}

\footnotetext{
Pensyarah Kanan, Pusat Pengajian Perakaunan, Fakulti Ekonomi dan Pengurusan, Universiti Kebangsaan Malaysia, 43600 Bangi, Selangor Darul Ehsan. Tel: 03-89215748, Faks: 03-89213162, e-mel: harlina@ukm.edu.my.
} 
Akhir sekali, penulis mencadangkan bentuk kaedah pengiklanan berhubung bidang kepakaran yang wajar dikuatkuasakan oleh Majlis Peguam.

Kata kunci: Pengiklanan, perkhidmatan guaman, bidang kepakaran, klien.

In the context of advertising by lawyers, it is the obligation of the legal profession to educate the public, especially those who are in the middle and low income group, of the existence and availability of legal services to help them solve legal problems. Thus, advertisement by legal services should contain information relevant to the public domain. However, in view of the publicity rules governing the legal professions Malaysia, the information which can be advertised are largely limited to attorney bios and details about the firm and the firms' partner. Information which must be made know to the public eg; those which may help the public to compare the services in the market and choose the services of lawyers which are appropriate to their needs, cannot be advertised. One is the information on the areas of expertise of lawyers. Based on content analysis method, this paper discusses the restrictions to advertise areas of expertise as contained in the rules governing the legal profession publicity Malaysia, and to make comparisons with the regulations in force in the United States, the United Kingdom (England \& Wales) and Australia (New South Wales). Based on simple sampling, questionnaire to survey public perception and counsel regarding this issue were distributed and the findings were presented in a descriptive manner. The results showed that the majority of the lawyers and the public have a perception that the information about the field of expertise is the appropriate information to be advertised by a lawyer. Finally, the authors suggest that the method of advertising on the areas of expertise that should be enforced by the Bar Council

\section{Pengenalan}

Secara umumnya, bagi rata-rata perkhidmatan profesional, selain memberi penekanan terhadap kelakuan ahli profesion, penekanan terhadap bidang kepakaran turut dititikberatkan. Kepakaran seseorang peguam misalnya, bergantung kepada ilmu pengetahuan dan tahap kemahiran yang tinggi serta pengalaman yang luas dalam 
bidang undang-undang tertentu. Bagi bakal pengguna perkhidmatan undang-undang, maklumat mengenai bidang kepakaran seseorang peguam adalah maklumat yang penting untuk diketahui sebelum membuat keputusan untuk memilih peguam mana yang layak untuk mengendalikan kesnya. Dalam kajian oleh Smith \& Meyer ${ }^{1}$ mengenai kriteria pemilihan peguam, walaupun sebahagian besar responden terbabit membuat pemilihan berdasarkan saranan rakan, kajian mendapati bahawa mereka lebih menggemari jika bidang kepakaran seseorang peguam dan kos perkhidmatannya diiklankan secara spesifik.

Namun begitu, melihat kepada kaedah publisiti yang mengawal profesion guaman Malaysia, maklumat mengenai bidang kepakaran seseorang peguam tidak boleh diiklankan. ${ }^{2}$ Ini kerana, peguam yang membuat publisiti mengenai amalannya hanya boleh mengiklankan 'maklumat yang diluluskan' seperti mana yang disenaraikan dalam kaedah 2 Kaedah-Kaedah Profesion Undang-Undang (Publisiti) 2001 dan keputusan 5.17 Keputusan-keputusan Majlis Peguam. Sebahagian besar 'maklumat yang diluluskan' ini terbatas kepada biodata peguam serta butiran mengenai firma dan rakan kongsi peguam. Larangan mengiklankan bidang kepakaran peguam ini telah melucutkan hak fundamental pihak awam dalam menilai dan memilih peguam. Ini kerana, salah satu hak pengguna yang diiktiraf sejagat ialah hak untuk mendapatkan maklumat mengenai sesuatu barangan atau perkhidmatan. ${ }^{3}$ Masyarakat pengguna perlu diberitahu tentang fakta yang relevan, tepat, terkini dan lengkap mengenai sesuatu barangan atau perkhidmatan bagi membolehkan mereka bertindak dengan bijak dan bertanggung jawab dalam membuat pemilihan terbaik. Ia juga bertujuan untuk memastikan

\footnotetext{
R.E. Smith \& T.S. Meyer, 'Attorney advertising: a consumer perspective' (1980) 44 (Spring) Journal of Marketing, hlm 56 - 63.

2 Kaedah 5(1)(b)(i) Kaedah-Kaedah Profesion Undang-Undang (Publisiti) 2001.

3 Hak untuk mendapat maklumat, hak untuk mendapat keselamatan, hak untuk memilih dan hak untuk bersuara merupakan empat hak pengguna yang diiktiraf buat pertama kalinya dalam Deklarasi Hak Pengguna yang diisytiharkan oleh mendiang presiden Amerika Syarikat John F. Kennedy pada 15 Mac 1962. Kini, menerusi pergerakan pengguna Consumers International (dahulu ialah International Organization of Consumers Union), empat lagi hak pengguna ditambah iaitu hak untuk mendapat keperluan asas, hak untuk mendapat ganti rugi, hak untuk mendapat pendidikan pengguna dan hak untuk mendapat persekitaran yang sihat. http://www.consumersinternational.org (11 Disember 2008).
} 
agar barangan atau perkhidmatan yang dibeli pengguna menepati keperluan dan bersesuaian dengan tujuan pembelian. Hak terhadap maklumat ini boleh melindungi pengguna daripada sebarang penipuan, iklan yang menyeleweng, pelabelan yang mengelirukan dan amalan perniagaan yang tidak beretika. ${ }^{4}$

Lantas, ketiadaan publisiti mengenai bidang kepakaran peguam menjadikan pihak awam tidak mengetahui tentang kebolehan dan kepakaran seseorang peguam, sedangkan maklumat sebeginilah yang perlu didedahkan bagi membolehkan pihak awam membuat penilaian dan pemilihan yang tepat. Kajian oleh American Bar Association, ${ }^{5}$ mendedahkan bahawa 48.3 peratus responden tidak menggunakan perkhidmatan guaman kerana mereka tidak tahu di mana dan bagaimana hendak mencari dan mendapatkan khidmat peguam yang benar-benar kompeten untuk mewakili mereka. Dapatan ini menunjukkan bahawa maklumat mengenai bidang kepakaran itu sangat penting diketahui pihak awam khususnya bakal klien demi mengelakkan mereka daripada memilih peguam secara sembarangan atau berlandaskan kriteria yang salah.

Kertas kerja ini menyingkap kepincangan yang terkandung dalam Kaedah-Kaedah Profesion Undang-Undang (Publisiti) 20016 (selepas ini dirujuk sebagai 'Kaedah Publisiti') berhubung pengiklanan bidang kepakaran oleh peguam. Penulis merujuk pendekatan yang diambil oleh persatuan-persatuan peguam di Amerika Syarikat, United Kingdom (England \& Wales) dan Australia (New South Wales) sebagai perbandingan dengan pendekatan yang dilaksanakan oleh Majlis Peguam Malaysia. Ketiga-tiga negara ini dipilih kerana ia telah meliberalkan kaedah publisiti yang mengawal profesion guamannya secara berperingkat semenjak tiga dekad yang lalu, justeru mempunyai banyak pengalaman berhubung kaedah publisiti oleh peguam yang boleh dijadikan sebagai panduan. Kod American Bar Association yang dirujuk ialah Model Code of Professional

Lihat hak pengguna terhadap maklumat dalam laman sesawang KPDNKK di http:// www.kpdnkk.gov.my/index.php?option=com_content\&task=view\&id=248\&Itemid=268 25Disember 2010) dan laman sesawang FOMCA di http://www.fomca.org.my/v2/index. php/portal-pengguna/hak-hak-pengguna (25 Disember 2010).

5 Curran, B.A. \& Spalding F.O. Preliminary Report of a National Survey by the Special Committee to Survey Legal Needs of the ABA. (Chicago: American Bar Foundation, 1980), hlm $85-86$.

6 PU(A) $345 / 2001$. 
Responsibility (selepas ini dirujuk sebagai 'Model Code') ${ }^{7}$ dan Model Rules of Professional Conduct (selepas ini dirujuk sebagai 'Model Rules'), manakala kaedah bar negeri yang dirujuk ialah Rules Regulating the Florida Bar. Manakala, peraturan England \& Wales yang dirujuk ialah Solicitors' Code of Conduct 2007, dan bagi New South Wales, penulis merujuk Legal Profession Act 2004. Dapatan soal selidik berhubung persepsi awam dan peguam mengenai isu ini turut dipaparkan. Seterusnya, penulis menyarankan beberapa penambahbaikan yang boleh dilakukan oleh Majlis Peguam terhadap kaedah publisiti yang mengawal profesion guaman berkaitan hal ini. Sebagai penutup, penulis menyimpulkan perbincangan secara keseluruhan.

\section{Kaedah Berhubung Pengiklanan Bidang Kepakaran oleh Peguam di Amerika Syarikat, United Kingdom, Australia dan Malaysia}

\section{Amerika Syarikat}

Bagi memastikan pihak awam tidak terkeliru atau terpedaya dengan maklumat berhubung bidang kepakaran seseorang peguam, pihak profesion telah melarang sebarang pernyataan mengenai kepakaran dalam bidang undang-undang tertentu melainkan jika dakwaan tersebut adalah benar dan boleh ditentusahkan. Lantaran itu di Amerika Syarikat, jika sesebuah negeri membenarkan pernyataan sedemikian, negeri tersebut mestilah mempunyai standard atau kaedah tertentu dalam mengiktiraf kepakaran. Model Code sendiri melarang peguam menonjolkan dirinya sebagai pakar, atau

\footnotetext{
Model Code ini mula diterima pakai oleh House of Delegates of the American Bar Association pada 12 Ogos 1969.

8 Model Rules ini mula diterima pakai oleh House of Delegates of the American Bar Association pada 2 Ogos 1983. Ia digubal oleh American Bar Association memandangkan terdapatnya perubahan yang ketara dalam profesion dan semakan semula ke atas Model Code adalah tidak munasabah. Ia bertujuan untuk memastikan peraturan berkaitan publisiti oleh peguam memenuhi keperluan profesion guaman yang semakin berkembang, di samping menyediakan rangka kerja dan bertindak sebagai model kepada negeri-negeri dalam membuat peraturan masing-masing. Hari ini, walaupun sebahagian besar daripada negeri-negeri di Amerika Syarikat menggubal kaedah etika untuk peguamnya berdasarkan peruntukan Model Rules, tetapi tiada negeri yang menerima pakainya secara verbatim. Terdapat juga beberapa negeri yang masih menerima pakai peruntukan Model Code.
} 
menjalankan amalan dalam bidang undang-undang tertentu atau membataskan amalannya, kecuali dalam dua bidang iaitu paten dan tanda niaga; ${ }^{9}$ melainkan jika mendapat pengiktirafan dan kelulusan daripada agensi bar negeri untuk berbuat demikian. ${ }^{10}$

Persoalan yang timbul di sini, jika seseorang peguam menyatakan bahawa beliau menjalankan amalan dalam bidang undang-undang tertentu atau membataskan amalannya, adakah ini secara tidak langsungnya membawa maksud bahawa peguam itu adalah pakar dalam bidang berkenaan? Misalnya, jika seseorang peguam menawarkan perkhidmatannya dalam lima bidang undangundang tertentu, adakah ini bermakna bahawa peguam itu adalah pakar dalam kelima-lima bidang tersebut? Atau jika peguam itu mendakwa bahawa beliau membataskan amalannya, atau menumpukan perhatian kepada lima bidang berkenaan, adakah ini secara tersiratnya bermaksud bahawa beliau adalah pakar dalam kelima-lima bidang tersebut? Dengan kata lain, dalam situasi yang bagaimanakah seseorang peguam dianggap menyenaraikan bidang amalannya secara sah tanpa, secara tersiratnya, mendakwa dirinya sebagai pakar dalam bidang yang berkenaan?

Model Rules membenarkan seseorang peguam untuk mengkomunikasikan kepada pihak awam bahawa beliau menjalankan amalan atau tidak menjalankan amalan dalam bidang undang-undang tertentu. ${ }^{11}$ Ini bermakna, jika seseorang peguam hanya menjalankan amalan dalam bidang-bidang tertentu, atau tidak akan menerima kes atau masalah kecuali yang berkaitan bidang khusus tersebut, peguam itu boleh menyatakan sedemikian. ${ }^{12}$

Dalam kes Zauderer v. Office of Disciplinary Counsel, ${ }^{13}$ peguam Zauderer yang mengiklankan amalannya dalam surat khabar telah bertanyakan kepada pembaca sama ada mereka pernah menggunakan peralatan intrauterine Dalkon Shield untuk mengawal kehamilan. Iklan tersebut selanjutnya menyatakan bahawa "... our law firm is presently representing women on such cases," dan menawarkan

DR 2-105(A)(1) Model Code of Professional Responsibility 1969.

DR 2-105(A)(2) \& (3) Model Code of Professional Responsibility 1969.

Kaedah 7.4(a) Model Rules of Professional Conduct 1983.

Kaedah 7.4 Model Rules of Professional Conduct 1983 - Comment.

[1985] 105 S. Ct. 2265. 
maklumat percuma kepada pengguna peralatan tersebut. Dalam mengetepikan pandangan yang menyatakan bahawa iklan tersebut telah menonjolkan Zauderer sebagai pakar dalam mengendalikan kes berhubung Dalkon Shield, Mahkamah Agung Amerika Syarikat menegaskan bahawa pihak Bar negeri tidak boleh menghalang seseorang peguam daripada membuat pernyataan sesuatu fakta yang tepat mengenai amalannya hanya kerana terdapatnya kemungkinan bahawa pihak awam akan mentaabir kepakaran dalam bidang undang-undang yang dinyatakan. ${ }^{14}$

Namun begitu, jika peguam menggunakan istilah 'specialist', atau frasa 'practices a specialty' atau 'specializes in particular fields', pernyataan sebegini mestilah tidak palsu atau mengelirukan. ${ }^{15}$ Justeru, demi mengelak sebarang pemalsuan atau kekeliruan, pernyataan tentang kepakaran perlu dilakukan menurut syarat yang ditetapkan oleh Model Rules, iaitu seseorang peguam hanya boleh disahkan sebagai pakar oleh organisasi yang diluluskan oleh pihak berkuasa negeri yang berkaitan atau yang diakui secara rasmi oleh pihak American Bar Association, dan nama organisasi yang membuat pengesahan itu mestilah dinyatakan dengan jelas dalam komunikasi tersebut. ${ }^{16}$

Di Florida misalnya, seseorang peguam boleh menyatakan dalam iklannya bahawa beliau 'does or does not practice in particular fields of law', namun iklan tersebut tidak boleh menyatakan atau secara tersiratnya menyatakan bahawa peguam tersebut adalah 'certified', 'board certified', 'expert', atau 'specialist' dalam sesuatu bidang undang-undang melainkan jika kepakaran peguam dalam bidang berkenaan telah ditentusahkan oleh Florida Bar, State Bar lain, atau organisasi lain yang diiktiraf oleh Florida Bar. ${ }^{17}$ Di Montana, Mahkamah Agung dalam kes In re Mountain Bell Advertising ${ }^{18}$ berpendapat bahawa peguam yang mendakwa dirinya sebagai pakar dalam mana-mana bidang yang dipilih dalam ketiadaan prosedur pengesahan di pihak negeri hanya akan mengelirukan pihak awam.

Ibid. halaman 2276.

Kaedah 7.4 Model Rules of Professional Conduct 1983 - Comment.

Kaedah 7.4(d) Model Rules of Professional Conduct 1983.

Kaedah 4-7.2(c)(6)(A) - (C) Rules Regulating the Florida Bar.

18 [1979] 185 Mont. 68, 604 P.2d 760. 


\section{United Kingdom (England \& Wales)}

Bagi England \& Wales pula, Solicitors' Code of Conduct 2007 tidak menyenaraikan secara spesifik jenis maklumat yang boleh diiklankan. Seseorang peguamcara boleh membuat publisiti mengenai amalannya atau amalan firmanya dan publisiti tersebut mestilah tepat dan tidak mengelirukan. ${ }^{19}$ Ini bermakna, peguamcara di England \& Wales boleh mengiklankan apa jua maklumat, termasuk bidang kepakarannya, dalam apa jua cara dengan syarat pengiklanan tersebut mestilah tepat dan tidak mengelirukan pihak awam.

\section{Australia (New South Wales)}

Begitu juga di New South Wales, Legal Profession Act 2004 tidak melarang seseorang peguambela atau peguamcara untuk membuat iklan dalam apa jua cara yang dia fikirkan wajar, tertakluk kepada kaedah di bawah seksyen $85 .{ }^{20}$ Namun begitu, iklan yang dibuat mestilah tidak palsu, tidak mengeliru atau tidak memperdaya, ${ }^{21}$ atau tidak bertentangan dengan Competition and Consumer Act atau peraturan lain. ${ }^{22}$ Ia seterusnya memperuntukkan bahawa seseorang peguambela atau peguamcara tidak boleh mengiklan atau mengemukakan dirinya sebagai seorang pakar atau menawarkan perkhidmatan pakar, melainkan jika peguambela atau peguamcara itu mempunyai kepakaran dan pengalaman berkaitan yang diiktiraf oleh skim akreditasi yang dikendali atau diluluskan oleh Bar Council atau Law Society Council. ${ }^{23}$ Ini bermakna, seseorang peguam tidak dilarang untuk mengiklankan kepakarannya, dengan syarat kepakaran tersebut mendapat pengiktirafan oleh persatuan peguam yang berkenaan.

\section{Malaysia}

Di Malaysia, berdasarkan Kaedah Publisiti, seseorang peguam atau firma boleh menyatakan bidang amalannya dalam publisiti yang dibuatnya. ${ }^{24}$ Antara bidang amalan yang sering kali dinyatakan

\footnotetext{
Kaedah 7.01 Solicitors' Code of Conduct 2007.

Seksyen 84(1) Legal Profession Act 2004.

1 Seksyen 84(2)(a) Legal Profession Act 2004.

22 Seksyen 84(2)(b) Legal Profession Act 2004.

23 Seksyen 86 Legal Profession Act 2004.

24 Kaedah 6 Kaedah-Kaedah Profesion Undang-Undang (Publisiti) 2001.
} 
oleh peguam dalam publisiti yang dibuat, misalnya menerusi laman sesawang Majlis Peguam, termasuklah undang-undang komersial, undang-undang perbankan dan kewangan, undang-undang-undang kebankrapan dan insolvensi, undang-undang jenayah, undangundang kekeluargaan dan perceraian, undang-undang pentadbiran dan perlembagaan, undang-undang perkapalan dan admiralti, undang-undang harta intelek, kemalangan dan kecederaan diri, dan litigasi sivil..$^{25}$

Namun begitu, dalam menyatakan tentang bidang amalan, terdapat sesetengah peguam yang menggunakan istilah seperti 'experts' dan 'specializes', yang mana istilah ini memberi gambaran kepada pihak awam bahawa mereka adalah pakar dalam bidang yang berkenaan. Misalnya, laman sesawang firma Joseph \& Partners ${ }^{26}$ antara lain menyatakan bahawa "Joseph \& Partners is a boutique law firm established in 2002 that specializes in five key practice areas ..." dan "as one of the country's foremost experts in Maritime law ..." Sedangkan, mendakwa diri atau firma sebagai pakar perunding atau pakar dalam mana-mana bidang amalan adalah dilarang sama sekali oleh Kaedah Publisiti. ${ }^{27}$

Walau bagaimanapun, penulis berpendapat bahawa larangan ini hanya akan menyebabkan pihak awam khususnya bakal klien tidak berpeluang atau sukar untuk mengetahui kepakaran yang dimiliki seseorang peguam, dan ini akan menjadikan pihak awam beranggapan bahawa semua peguam adalah sama daripada segi mutu kerja dan ilmu pengetahuan. Natijahnya, golongan peguam berkemungkinan menjadi kurang inisiatif untuk membangunkan kepakaran mereka sedangkan mempunyai kepakaran dalam bidang tertentu adalah penting lebih-lebih lagi bagi firma kecil yang berhasrat untuk menarik klien korporat. ${ }^{28}$

Lantaran itu, membangunkan kaedah yang efisien berhubung bidang kepakaran ini sangatlah relevan mengambil kira perkembangan semasa yang menuntut persaingan dinamis dan progresif di kalangan peguam dan firma tempatan. Menurut Abdul Aziz bin Abdul Rahman,

25 Lihat laman sesawang Majlis Peguam di http://www.malaysianbar.org.my.

26 Lihat http://www.jnplaw.my/(14 Ogos 2010).

27 Kaedah 5(1)(b)(i) Kaedah-Kaedah Profesion Undang-Undang (Publisiti) 2001.

28 Morgan, 'How Small Firms Can Attract Corporate Litigation' (1984) (Oct) American Bar Association Journal, hlm 60-61. 
peredaran masa menuntut peguam tempatan untuk membangunkan kepakaran dalam bidang tertentu demi mempertahankan standard profesionalisme yang tinggi. Menurutnya lagi, setiap peguam perlu menjadi efisien daripada segenap aspek dalam menghadapi cabaran persaingan yang pastinya akan menjadi semakin sengit pada masa hadapan. ${ }^{29}$

Meninjau dunia amalan profesional lain, misalnya golongan doktor, menjalankan amalan dan membuat publisiti mengenai bidang kepakaran adalah perkara biasa. Malah, klinik-klinik dan hospital-hospital pakar dibangunkan bagi memenuhi keperluan masyarakat. Seperti doktor, seseorang peguam juga mempunyai bidang kepakaran tertentu. Seseorang pesakit tidak akan menemui pakar telinga, hidung dan kerongkong apabila mempunyai masalah jantung berlubang, begitu juga seseorang yang memerlukan nasihat guaman berhubung perniagaan dan percukaian tidak sewajarnya mendapatkan khidmat peguam yang pakar dalam bidang jenayah. Tetapi malangnya, tidak seperti pesakit jantung yang boleh mencari pakar sakit jantung dengan mudah, seseorang yang memerlukan khidmat guaman mengalami kesukaran dalam mengenal pasti kepakaran seseorang peguam lantaran para peguam dilarang mengiklankan bidang kepakaran mereka.

Justeru, tidak syak lagi, maklumat mengenai bidang kepakaran merupakan maklumat yang amat penting untuk diketahui pihak awam terutamanya bakal klien. Ini kerana, bakal klien perlu mencari dan memilih peguam yang benar-benar layak dan sesuai untuk mengendalikan kes atau masalah perundangan yang dihadapi. Tambahan pula, disebabkan persaingan di kalangan peguam yang semakin meningkat pada alaf ini, golongan peguam semakin berminat membataskan amalan mereka kepada bidang-bidang tertentu dengan tujuan untuk mencipta niche serta menambah kemahiran dan kecekapan. Oleh itu, mengenakan kaedah publisiti yang terlalu ketat hanya akan menyulitkan pihak peguam untuk mengkomunikasikan bidang kepakaran mereka sekaligus menyekat penyampaian maklumat berguna kepada pihak awam.

29 Abdul Aziz Abdul Rahman, 'Tan Sri Abdul Aziz Abdul Rahman Speaks: Lawyers' Advertising Rules', 27 Ogos 2010. http://www.mmail.com.my/content/47702-lawyersadvertising-rules (19 Oktober 2010). 
Bagi memastikan maklumat mengenai bidang kepakaran tidak dipalsukan, atau pernyataan mengenainya tidak mengeliru atau memperdaya pihak awam, atau dengan kata lain bagi menentusahkan kepakaran seseorang peguam dalam sesuatu bidang, pihak Majlis Peguam boleh mengwujud dan membangunkan suatu sistem penilaian atau pengiktirafan bidang kepakaran seperti yang dilaksanakan, contohnya di Florida atau lain-lain negeri di Amerika Syarikat dan di New South Wales, Australia. Pengalaman lebih tiga puluh tahun dalam membangunkan kaedah publisiti yang efisien dan efektif menjadikan pendekatan yang diambil oleh persatuan peguam di negara berkenaan sebagai relevan untuk dijadikan sebagai garis panduan.

\section{Persepsi Awam dan Peguam Berhubung Kesesuaian Mengiklan Bidang Kepakaran}

Penulis turut mengumpul maklumat berhubung perkara ini menerusi dua soal selidik yang dijalankan secara berasingan. Dalam soal selidik pertama, ${ }^{30}$ berdasarkan pensampelan mudah, sebanyak 370 naskhah soal selidik telah diedarkan secara mel biasa kepada peguam di seluruh Semenanjung Malaysia secara pro rata mengikut jumlah peguam di setiap negeri. Daripada jumlah tersebut, seramai 198 peguam (53.5\%) memberi maklum balas. Walaupun soal selidik ini merangkumi pelbagai isu berhubung persepsi peguam terhadap publisiti dalam profesion guaman, hanya dapatan mengenai isu pengiklanan bidang kepakaran peguam yang diketengahkan dalam kertas kerja ini.

Manakala dalam soal selidik kedua, ${ }^{31}$ berdasarkan pensampelan mudah, sebanyak 400 naskhah soal selidik telah diedarkan secara serahan tangan kepada masyarakat awam di sekitar Lembah Klang. Daripada jumlah tersebut, seramai 386 orang (96.5\%) memberi maklum balas. Walaupun soal selidik ini merangkumi pelbagai isu berhubung persepsi awam terhadap publisiti dalam profesion guaman, hanya dapatan mengenai isu pengiklanan bidang kepakaran peguam yang diketengahkan dalam kertas kerja ini.

30 Soal selidik ini dijalankan pada tahun 2009 oleh penulis sebagai sebahagian daripada keperluan untuk memperoleh Ijazah Doktor Falsafah, yang mana dapatannya telah digunakan untuk memperkukuh tesis penulis.

31 Soal selidik ini dijalankan pada tahun 2012 di bawah Geran Galakan Penyelidik Muda (GGPM-2011-061) yang diperoleh daripada Universiti Kebangsaan Malaysia. 
Dalam kedua-dua soal selidik, pihak peguam dan awam ditanya soalan berikut:

Selain daripada maklumat biografi, adakah sesuai bagi peguam dan firma guaman untuk membuat publisiti mengenai bidang kepakarannya?

Dapatan untuk kedua-dua soal selidik tersebut dipaparkan dalam Jadual 1 di bawah.

Jadual 1

Persepsi peguam dan awam mengenai pengiklanan bidang kepakaran peguam

\begin{tabular}{lccccc}
\hline & $\begin{array}{c}\text { Sangat } \\
\text { Tidak } \\
\text { Sesuai } \\
(\%)\end{array}$ & $\begin{array}{c}\text { Tidak } \\
\text { Sesuai } \\
(\%)\end{array}$ & $\begin{array}{c}\text { Tidak } \\
\text { Pasti } \\
(\%)\end{array}$ & $\begin{array}{c}\text { Sesuai } \\
(\%)\end{array}$ & $\begin{array}{c}\text { Sangat } \\
\text { Sesuai } \\
(\%)\end{array}$ \\
\hline $\begin{array}{l}\text { Persepsi } \\
\text { peguam }\end{array}$ & 2.5 & 6.6 & 1.0 & 57.6 & 32.3 \\
$\begin{array}{l}\text { Persepsi } \\
\text { awam }\end{array}$ & 0.8 & 1.3 & 8.8 & 54.1 & 35.0 \\
\hline
\end{tabular}

Dapatan di atas jelas menunjukkan bahawa majoriti pihak peguam dan awam mempunyai persepsi bahawa maklumat mengenai bidang kepakaran adalah maklumat yang sesuai untuk diiklankan oleh peguam. Malah, dalam komentar tambahan, salah seorang responden peguam menyatakan bahawa salah satu sebab mengapa sesetengah peguam meninggalkan profesion adalah kerana mereka tidak dibenarkan untuk membuat publisiti mengenai bidang kepakaran mereka. Menurut salah seorang responden peguam lagi:

Publicity is an ongoing process and we need to keep up with other jurisdictions. Bar Council must constantly update the rules. We must not put our legal profession in a disadvantage position as compared to other jurisdictions that have embraced more liberal publicity rules. But at the same time, we must balance this moderation with our ethics and the fact that the legal 
profession is a professional practice and not a mere business. This is a challenge for us in the profession.

Begitu juga di pihak responden awam, ada yang berpendapat bahawa publisiti oleh peguam mestilah memperincikan secara khusus tentang bidang kepakaran dan tidak sekadar menyatakan bidang amalan peguam sahaja. Menurut mereka, jika peguam di Malaysia boleh mengiklankan bidang kepakarannya, ia bukan sahaja dapat membantu bakal klien dalam memilih peguam yang tepat untuk mengendalikan masalah perundangan yang dihadapi, malah dapat mendidik masyarakat awam untuk lebih memahami tentang hak-hak mereka di sisi undang-undang. Tambah responden awam lagi, dalam konteks dunia tanpa sempadan, peguam Malaysia boleh dikenali di peringkat antara bangsa sekiranya ada publisiti yang baik mengenai bidang kepakaran, contohnya kepakaran dalam mengendalikan keskes berkaitan kewangan dan perbankan Islam. Memetik ungkapan menarik salah seorang responden awam:

The Bar Council should revise and liberalize their rules so as to make it consistent with current situation (globalization and open market). Other jurisdictions have already updated their rules and allow their lawyers to publicize their services (but in a regulated manner), it would be a disadvantage to local lawyers if they are not given the same opportunity. Local people know more about foreign lawyers' expertise as compared to local lawyers.

\section{Saranan Penambahbaikan terhadap Kaedah Publisiti yang Mengawal Profesion Guaman Malaysia}

\section{Bidang Kepakaran}

Sekadar menyatakan bidang amalan tidak membawa maksud bahawa seseorang peguam itu adalah pakar dalam bidang amalan tersebut. Justeru, penulis mencadangkan agar publisiti mengenai bidang kepakaran dibenarkan. Namun begitu, bagi mengelak sebarang kekeliruan atau perdayaan, ${ }^{32}$ penulis menyarankan agar:

32 Publisiti yang mengeliru atau memperdayakan adalah dilarang di bawah kaedah 5(1)(a) (ii) Kaedah-Kaedah Profesion Undang-Undang (Publisiti) 2001. 
(a) Sebarang pernyataan tentang kepakaran mestilah benar dan boleh ditentusahkan. Oleh itu, Majlis Peguam hendaklah mempunyai standard atau kaedah tertentu dalam mengiktiraf kepakaran seseorang peguam dalam sesuatu bidang itu; ${ }^{33}$

(b) Hanya kepakaran yang telah diiktiraf oleh Majlis Peguam yang boleh diiklankan; dan

(c) Jika tiada pengiktirafan, hanya pernyataan mengenai bidang amalan dibenarkan dan dalam situasi ini, peguam hendaklah berhati-hati dalam menggunakan istilah atau frasa demi mengelak pihak awam mempercayai bahawa beliau adalah pakar dalam bidang yang berkenaan.

\section{Bidang Amalan}

Tidak ketinggalan, penulis turut mengemukakan saranan penambahbaikan berhubung publisiti mengenai bidang amalan. Ini kerana, berdasarkan kaedah sedia ada, walaupun bidang amalan termasuk dalam senarai 'maklumat yang diluluskan' di bawah kaedah 2 Kaedah Publisiti, para peguam dilarang membuat sebarang dakwaan bahawa dirinya adalah pakar dalam mana-mana bidang amalan yang dinyatakan. ${ }^{34}$ Oleh itu, penulis mencadangkan agar:

(a) Pernyataan mengenai bidang amalan mestilah mengelak daripada menggunakan istilah seperti 'pakar' ('expert' atau 'specialist'), atau frasa seperti 'mengamalkan pengkhususan' ('practices a specialty') atau 'mengkhusus dalam bidang tertentu' ('specializes in particular field'). Ini bagi mengelak pihak awam daripada membuat andaian bahawa peguam yang menyatakan sedemikian adalah seorang yang pakar dalam bidang berkenaan; dan

(b) Majlis Peguam hendaklah, menerusi komentar atau garis panduan yang dikeluarkan dari semasa ke semasa, ${ }^{35}$

33 Memandangkan peranan Majlis Peguam akan bertambah sekiranya para peguam dibenarkan untuk mengiklankan kepakaran mereka, penulis bercadang untuk mengkaji keperluan membangunkan bidang kepakaran oleh peguam dalam era globalisasi, juga keperluan untuk mengwujudkan standard atau kaedah untuk mengiktiraf kepakaran seseorang peguam dalam kajian penulis pada masa akan datang.

34 Kaedah 5(1)(b)(i) Kaedah-Kaedah Profesion Undang-Undang (Publisiti) 2001.

35 Seperti mana yang dilakukan oleh Model Rules of Professional Conduct 1983 yang menyediakan Comment untuk setiap kaedahnya, atau seperti Solicitors ' Code of Conduct 2007 yang menyediakan Guidance to rule 7 - Publicity bagi menjelaskan dengan lebih lanjut mengenai sesuatu peruntukan kaedah itu. Penulis mendapati bahawa comment dan guidance ini sangat membantu dalam menambah kefahaman peguam mengenai maksud setiap kaedah yang diperuntukkan. 
menjelaskan hal ini atau mencadangkan istilah atau frasa yang sesuai bagi mengelak berlakunya sebarang pelanggaran terhadap Kaedah Publisiti berhubung bidang amalan, ataupun Majlis Peguam boleh memberikan contoh-contoh istilah atau frasa yang tidak sesuai disebabkan kecenderungannya untuk mengeliru atau memperdaya pihak awam. Misalnya, dalam menyatakan kesediaan untuk menerima tugasan dalam sesuatu bidang tertentu, peguam bolehlah menggunakan frasa seperti 'menerima tugasan dalam ...' ('accepting work in ...'), berbanding 'kami adalah pakar dalam ...' ('we are experts in ...').

\section{Kesimpulan}

Mengimbas kembali kes Metramac Corporation Sdn. Bhd. v. Fawziah Holdings Sdn. Bhd., ${ }^{36}$ apabila pihak responden dalam kes ini meminta Queen's Counsel, Cherie Booth, untuk mewakilinya berdasarkan kepakaran peguam itu dalam bidang undang-undang awam dan hak asasi manusia, tindakan tersebut telah ditentang oleh beberapa pihak iaitu pihak apellan, Tun Daim Zainuddin, Datuk Halim Saad, Peguamcara Negara, Majlis Peguam dan Kuala Lumpur Bar Committee. Penentangan tersebut dibuat atas alasan bahawa peguam asing tidak boleh menjalankan amalan di Malaysia jika kepakaran yang diperlukan itu dimiliki oleh peguam tempatan. ${ }^{37}$ Persoalan yang dibangkitkan di sini ialah, bagaimanakah pihak responden boleh mengetahui tentang kepakaran peguam tempatan jika para peguam di Malaysia dilarang untuk mengiklankan kepakaran mereka? Disebabkan ketiadaan publisiti mengenai bidang kepakaran peguam tempatan, maka pihak responden dalam kes ini dan pihak awam secara umumnya lebih mengetahui kepakaran yang dimiliki peguam asing berbanding peguam tempatan.

Justeru, sudah tiba masanya bagi Majlis Peguam untuk meliberalkan kaedah publisitinya bagi membolehkan peguam tempatan untuk membuat publisiti mengenai bidang kepakarannya. Penambahbaikan wajar dilakukan terhadap Kaedah Publisiti dengan menghapus atau melonggarkan larangan dan sekatan yang berlebihan, yang tidak memberi sebarang manfaat kepada pihak profesion dan awam

(2006) 3 CLJ 177.

37 Seksyen 18 Akta Profesion Undang-Undang 1976. 
khususnya bakal klien. Seperti yang diluahkan oleh Loong Caesar dalam surat terbukanya kepada Majlis Peguam:

\begin{abstract}
...that our so-called ethical standards were never our own to begin with. This value system was foisted upon us by our colonial brethren who have since moved on and learnt better ways of doing things. Rather than resist these changes, we should establish new ethical and practice standards that are relevant and appropriate to our time. ${ }^{38}$
\end{abstract}

Hal ini selaras dengan keperluan semasa yang sedang menuju ke arah liberalisasi sektor perkhidmatan profesional dan pembukaan pasaran domestik. $^{39}$ Begitu juga, perkembangan teknologi maklumat dan komunikasi yang begitu pantas telah menjadikan apa jua maklumat boleh diakses tanpa sebarang sempadan. Jika peguam dan firma tempatan disekat daripada pelbagai sudut untuk mengiklankan kepakaran mereka, hal ini akan meletakkan peguam dan firma tempatan dalam situasi yang tidak mendapat faedah berbanding peguam dan firma asing.

\title{
Rujukan
}

Abdul Aziz Abdul Rahman. 2010. Tan Sri Abdul Aziz Abdul Rahman speaks: lawyers' advertising rules. 27 Ogos. http://www. mmail.com.my/content/47702-lawyers-advertising-rules [19 Oktober 2010].

38 Lau Yun Tseng, Lawyers - from Professionals to Salesmen, 2006. http://www. malaysianbar.org.my/legal_profession/lawyers_from_professionals_to_salesmen.html (2 April 2010).

39 Misalnya, sewaktu membuat pengumuman untuk membuka pasaran 27 sektor kecil perkhidmatan tanpa sebarang syarat pegangan ekuiti tempatan berkuat kuasa sertamerta sebagai usaha untuk menarik pelaburan asing, teknologi dan menjana peluang pekerjaan bertaraf tinggi, Kerajaan turut membenarkan 5 firma guaman asing yang pakar dalam bidang kewangan Islam untuk menawar perkhidmatan di negara ini sebagai sebahagian daripada usaha untuk membangunkan Malaysia sebagai hab kewangan Islam antarabangsa. Ia turut bertujuan untuk menjadikan sektor perkhidmatan lebih berdaya maju, lebih kompetitif dan bersaing pada peringkat antarabangsa. Johari Ibrahim, 'Buka 27 sektor kecil', Berita Harian, 23 April 2009, hlm 1-2. 
Curran, B.A. \& Spalding F.O. Preliminary Report of a National Survey by the Special Committee to Survey Legal Needs of the ABA. (Chicago: American Bar Foundation, 1980).

http://www.consumersinternational.org[11 Disember 2008].

http://www.fomca.org.my/v2/index.php/portal-pengguna/hak-hakpengguna 25 Disember 2010].

http://www.jnplaw.my/ [14 Ogos 2010].

http://www.kpdnkk.gov.my/index.php?option=com_content\&task= view\&id=248\&Itemid=268 [25 Disember 2010].

http://www.malaysianbar.org.my/areas-of-practice/[13 September 2009].

Johari Ibrahim. 2009. Buka 27 sektor kecil. Berita Harian, 23 April: 1-2.

Lau, Yun Tseng. 2006. Lawyers - from Professionals to Salesmen. http://www.malaysianbar.org.my/legal_profession/lawyers from_professionals_to_salesmen.html[2 April 2010].

Morgan. 1984. How small firms can attract corporate litigation. American Bar Association Journal (Oct): 60 - 61.

Smith, R.E. \& Meyer, T.S. 1980. Attorney advertising: a consumer perspective. Journal of Marketing 44(Spring): 56-63. 